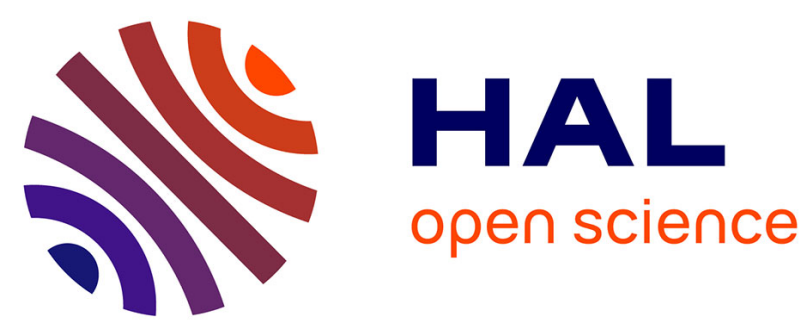

\title{
Diode-pumped Yb:Sr3Y(BO3)3 femtosecond laser
}

Frédéric Druon, Sébastien Chenais, Pierre Raybaut, François Balembois, Patrick Georges, Romain Gaume, Gerard Aka, Bruno Viana, S. Mohr, D. Kopf

\section{To cite this version:}

Frédéric Druon, Sébastien Chenais, Pierre Raybaut, François Balembois, Patrick Georges, et al.. Diode-pumped Yb:Sr3Y(BO3)3 femtosecond laser. Optics Letters, 2002, 27 (3), pp.197-199. hal00761364

\section{HAL Id: hal-00761364 \\ https://hal-iogs.archives-ouvertes.fr/hal-00761364}

Submitted on 5 Dec 2012

HAL is a multi-disciplinary open access archive for the deposit and dissemination of scientific research documents, whether they are published or not. The documents may come from teaching and research institutions in France or abroad, or from public or private research centers.
L'archive ouverte pluridisciplinaire HAL, est destinée au dépôt et à la diffusion de documents scientifiques de niveau recherche, publiés ou non, émanant des établissements d'enseignement et de recherche français ou étrangers, des laboratoires publics ou privés. 


\title{
Diode-pumped $\mathrm{Yb}: \mathrm{Sr}_{3} \mathrm{Y}\left(\mathrm{BO}_{3}\right)_{3}$ femtosecond laser
}

\author{
F. Druon, S. Chénais, P. Raybaut, F. Balembois, and P. Georges \\ Laboratoire Charles Fabry de l'Institut d'Optique, Unité Mixte de Recherche 8051 du Centre National de la Recherche Scientifique, \\ Centre Universitaire d'Orsay, Bâtiment 503, 91403 Orsay, France
}

R. Gaumé, G. Aka, and B. Viana

Laboratoire de Chimie Appliquée de l'État Solide, Unité Mixte de Recherche 7574 du Centre National de la Recherche Scientifique, École Nationale Supérieure de Chimie Paris, 75231 Cedex 05, France

\author{
S. Mohr and D. Kopf \\ High Q Laser Production GmbH, Kaestel-Areal, 2. OG Kaiser-Franz-Josef-Strasse 61, A-6845 Hohenems, Austria
}

Received September 4, 2001

\begin{abstract}
We have developed a diode-pumped $\mathrm{Yb}^{3+}: \mathrm{Sr}_{3} \mathrm{Y}\left(\mathrm{BO}_{3}\right)_{3}$ (Yb:BOYS) laser generating 69-fs pulses, at a central wavelength of $1062 \mathrm{~nm}$. This laser is mode locked by use of a semiconductor saturable-absorber mirror and emits $80 \mathrm{~mW}$ of average power at $113 \mathrm{MHz}$. This is, to our knowledge, the first mode-locked Yb:BOYS laser and the shortest duration obtained from an ytterbium laser with a crystalline host. The central wavelength can be tuned from 1051 to $1070 \mathrm{~nm}$, for sub-100-fs pulses. We have also achieved an average power as high as $300 \mathrm{~mW}$ with pulse duration of $86 \mathrm{fs}$ at $1068 \mathrm{~nm}$. (C) 2002 Optical Society of America

OCIS codes: $140.4050,140.3480,140.5680,140.3070$.
\end{abstract}

The $\mathrm{Yb}^{3+}$ ion has been recognized for a few years now as a very interesting dopant for materials involved in solid-state laser development and especially in the ultrafast-laser field. First, because of their very simple electronic-level scheme based on only two manifolds, and because they can be diode pumped, Yb-doped materials have made possible the development of very efficient, simple, and compact directly diode-pumped lasers. ${ }^{1}$ Moreover, $\mathrm{Yb}$-doped materials exhibit-with respect to their Nd-doped counterparts, for example - relatively broad emission spectra, which makes them very attractive for use in the realm of ultrafast technology. ${ }^{2,3}$

From the point of view of developing diode-pumped ultrashort-laser systems, it is crucial to look for $\mathrm{Yb}$-doped materials with the broadest emission spectrum. ${ }^{2,4-6}$ Among them, $\mathrm{Yb}$ glasses exhibit very large emission bandwidths and thus have made possible the production of 58 -fs pulses, ${ }^{2}$ but the poor thermal properties and very low emission cross sections (Table 1) of these glasses make it very constraining to use them because of subsequently induced low gain and very strong thermal effects. It is thus interesting to investigate $\mathrm{Yb}$-doped crystals, which have a higher emission cross section and better thermal behavior (Table 1). The problem is that the crystalline structure also tends to keep the emission and absorption bands narrow (the emission bandwidth is only $10 \mathrm{~nm}$ wide for $\mathrm{Yb}: \mathrm{YAG}$, for example). The most appropriate material for ultrashort-pulse generation would therefore be a crystal with good spectroscopic and thermal properties but with spectral-emission broadness comparable to that of glasses.

In this Letter we report results obtained with a new crystal, $\mathrm{Yb}: \mathrm{Sr}_{3} \mathrm{Y}\left(\mathrm{BO}_{3}\right)_{3}$ (Yb:BOYS) ${ }^{8}$ The rising interest in this crystal is due to its numerous advantages and its good qualities compared with those of its competitors, mainly its excellent spectral properties. ${ }^{9}$ As shown in Fig. 1, the emission cross-section spectrum is actually quite broad, with a glasslike shape. Furthermore, the $\mathrm{Yb}$ :BOYS emission bandwidth is one of the broadest for an $\mathrm{Yb}$-doped crystal and is even broader than those of several Yb-doped glasses, such as Yb:phosphate (Table 1). In addition, the Yb:BOYS crystal also has relatively high emission cross section and thermal conductivity, comparable to those of other borate crystals such as Yb:GdCOB. Another interesting property of $\mathrm{Yb}$ :BOYS is its broad absorption peak $(6 \mathrm{~nm})$ at the zero phonon line, almost twice as broad as those of other crystals. This characteristic is significant in the case of diode pumping, because it loosens the constraint on the spectral linewidth of the high-power diode, whose spectral broadness can be a limiting factor for diode-pumped systems.

The combination of these properties, which have already been corroborated by experiments in the cw regime in terms of large tunability and high efficiency, ${ }^{10}$ makes the Yb:BOYS crystal the most suitable to date for the development of a very efficient ultrashort-pulse oscillator. In this Letter we report on our experiments in passive mode locking of an $\mathrm{Yb}$ :BOYS laser.

The experiment was performed with a 3-mm-long, antireflection-coated, 20\%-doped Yb:BOYS crystal. The pumping system was composed of one or two $1 \mu \mathrm{m} \times 100 \mu \mathrm{m}$ junction laser diodes emitting at $975 \mathrm{~nm}$ whose beams had been reshaped in the direction parallel to the diode-active area by use of a cylindrical afocal expander. Diode \#1 emitted $\mathrm{cw}$ power of $1.6 \mathrm{~W}$; its beam was collimated with a $15-\mathrm{mm}$ objective, reshaped with an $8 \times$ cylindrical afocal expander, and focused with an $80-\mathrm{mm}$ doublet. 
Table 1. Numerical Data on Typical Yb-Doped Materials Used in Femtosecond Oscillators

\begin{tabular}{|c|c|c|c|c|c|c|}
\hline Characteristic Parameters & YAG & $\mathrm{KYW}^{c}$ & $\mathrm{KGW}^{d}$ & Glass & $\mathrm{GdCOB}^{e}$ & BOYS \\
\hline Theoretical pulse duration (fs) & 118 & 50 & 47 & 33 & 27 & 19 \\
\hline Absorption bandwidth $(\mathrm{nm})$ & 3 & 3.5 & 3.5 & 7 & 3 & 6 \\
\hline Absorption bandwidth at the zero-line wavelength $(\mathrm{nm})$ & 968 & 981 & 981 & 975 & 976 & 975 \\
\hline Fluorescence lifetime (ms) & 0.95 & 0.7 & 0.75 & 1.3 & 2.6 & 1.1 \\
\hline Ref. & 2 & 6 & 7 & 2 & 5 & 8,9 \\
\hline
\end{tabular}

${ }^{a}$ To take into account the large overlap between the emission and the absorption spectra, we measured the emission bandwidth by considering the FWHM gain cross-section broadness for a partially excited-state population $(\beta=0.5)$.

${ }^{b}$ We obtained this result by pure Kerr-lens mode locking.

${ }^{c} \mathrm{KY}\left(\mathrm{WO}_{4}\right)_{2}$.

${ }^{d} \mathrm{KGd}\left(\mathrm{WO}_{4}\right)_{2}$.

${ }^{e} \mathrm{Ca}_{4} \mathrm{GdO}\left(\mathrm{BO}_{3}\right)_{3}$.

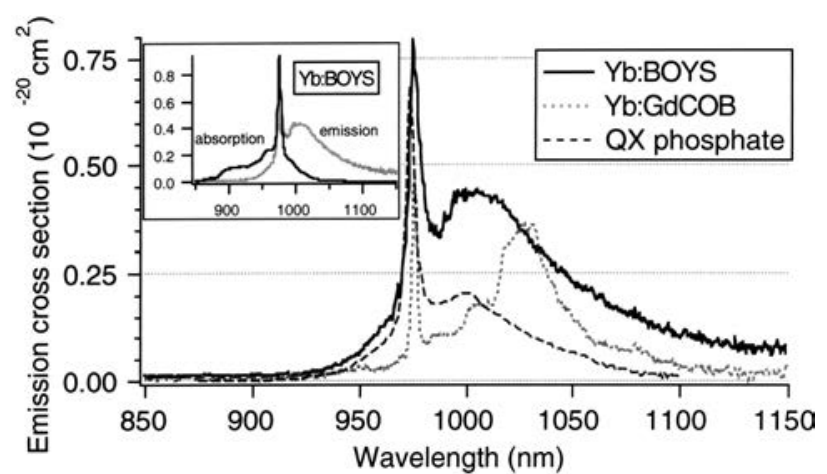

Fig. 1. Emission cross-section spectrum of Yb:BOYS compared with that of a typical Yb-doped glass, QX phosphate (Kigre, Inc.) and a borate crystal, Yb:GdCOB. Inset, emission and absorption cross spectra of $\mathrm{Yb}: \mathrm{BO}_{5}$.

Diode \#2 emitted cw power of $2 \mathrm{~W}$; its beam was collimated with an 8-mm aspherical lens, reshaped with a $4 \times$ cylindrical afocal expander, and focused with a 60-mm doublet. The incident pump power was $1.1 \mathrm{~W}$ with only diode \#1 and $2.5 \mathrm{~W}$ with both diodes. The cavity setup is illustrated in Fig. 2; the laser spot size in the Yb:BOYS crystal had a waist of $27 \mu \mathrm{m}$. The group-velocity dispersion introduced by the crystal was compensated for by a pair of SF10 prisms separated by $28 \mathrm{~cm}$. To initiate the mode-locking operation in the laser, we used a semiconductor saturable-absorber mirror (SESAM). ${ }^{11}$ To optimize the pulse fluence on the SESAM, we used a $300-\mathrm{mm}$ radius-of-curvature mirror to focus the cavity mode to a spot-size diameter of $80 \mu \mathrm{m}$ on the SESAM for single-diode pumping and a $500-\mathrm{mm}$ mirror with a spot-size diameter of $120 \mu \mathrm{m}$ for two-diode pumping. The advantage of using a SESAM rather than Kerr-lens mode locking is that we avoid the need for critical alignment, leading to a more stable laser. ${ }^{11}$ Moreover, the mode-locking instability is crucial, especially in the case of Yb-doped materials, which tend easily toward $Q$-switch regimes because of their long excited-state lifetimes. ${ }^{12}$

With this setup and when pumping with one (diode \#1), we obtained pulses as short as 69 fs FWHM, assuming a $\operatorname{sech}^{2}$ pulse shape (Fig. 3a). The corresponding spectrum (Fig. 3b) had an 18-nm FWHM bandwidth with a wavelength centered at $1062 \mathrm{~nm}$, which corresponds to the natural free-running wavelength. The time-bandwidth product was 0.333 (to be compared with 0.315 in the Fourier-transform case for sech $^{2}$ pulses). The average output power was $80 \mathrm{~mW}$ for a repetition rate of $113 \mathrm{MHz}$, which corresponds to an energy per pulse of $0.7 \mathrm{~nJ}$, or $10-\mathrm{kW}$ peak power. The mode-lock operation was stable for hours, without evidence of dropping out or passive $Q$ switching. The mode-locked regime was self-starting, with a transition time varying from 50 to $200 \mathrm{~ms}$. The stable mode-locked regime was achieved with greater than $22 \mathrm{~mW}$ of average output power. The

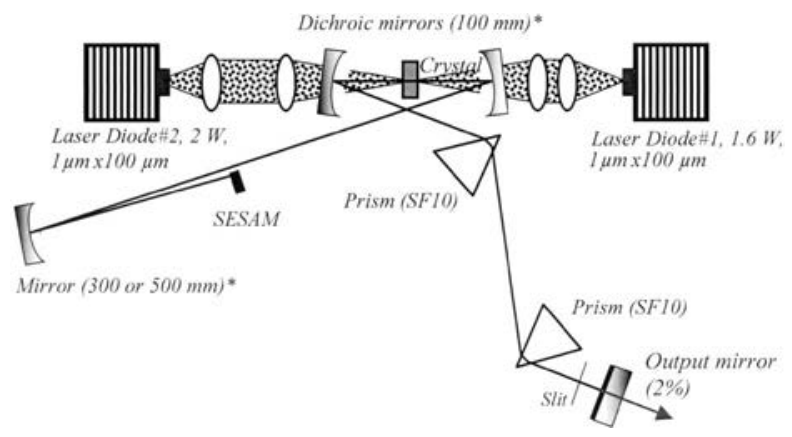

Fig. 2. Experimental setup of the femtosecond oscillator. Asterisks, values given for the radius of curvature.

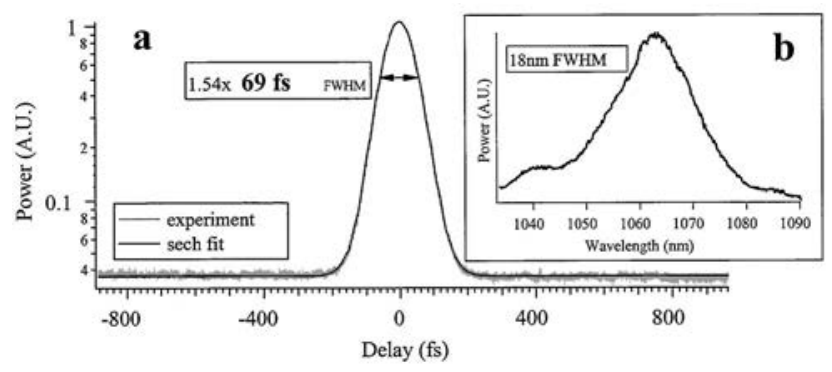

Fig. 3. a, autocorrelation, on a log scale, of 69 -fs pulses (assuming a sech ${ }^{2}$ fit). b, spectral power density corresponding to the same pulses. 

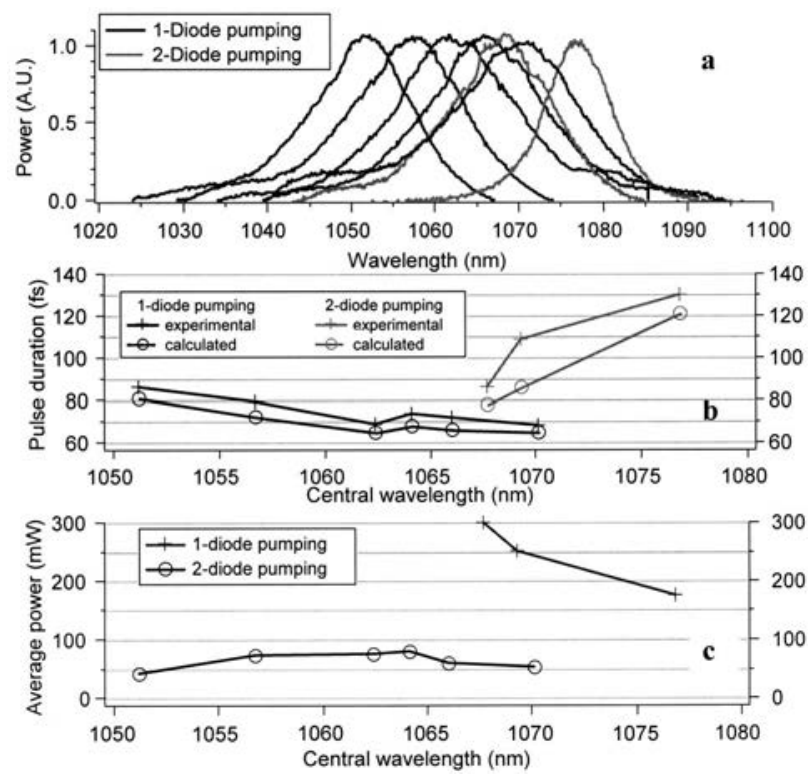

Fig. 4. Tunability of the Yb:BOYS femtosecond laser: a, pulse spectra; $b$, pulse duration measured experimentally with an autocorrelator and calculated by Fourier transform from the spectra, assuming no chirp in the phase; c, average power.

excellent stability of the mode-locked regime allowed straightforward tuning of the laser by translation of the slit located between the prism and the output coupler (Fig. 2). We thus obtained a range of tunability from 1051 to $1064 \mathrm{~nm}$, with a pulse duration shorter than 86 fs (Figs. 4a and 4b), which is to our knowledge the largest tunability in this sub-100-fs range for an Yb-doped material. Moreover, by increasing the intracavity power (changing the output coupler), we extended this tunability continuously up to $1070 \mathrm{~nm}$, with a tunability of $8 \mathrm{~nm}$ (and for sub-75-fs pulses), which then leads a total tunability of $19 \mathrm{~nm}$.

To increase the power of the laser, we pumped the crystal from both sides. We obtained 86-fs pulses with an average power of $300 \mathrm{~mW}$ (Fig. 4c) at a repetition rate of $105 \mathrm{MHz}$. The spectrum was centered at $1068 \mathrm{~nm}$ (using the slit) and was $15 \mathrm{~nm}$ wide (Figs. 4a and $4 \mathrm{~b}$ ). In the two-diode-pumping configuration, the stable mode-locked domain allowed a tunability of $9 \mathrm{~nm}$ from 1068 to $1076 \mathrm{~nm}$. The increase of the wavelength with two-diode pumping compared with single-diode pumping can be explained by the fact that, if we try to tune the laser to shorter wavelength, the mode-locked regime becomes unstable. In fact, when the central wavelength gets closer to the natural wavelength $(1062 \mathrm{~nm})$, the intracavity power rises to a level at which a cw regime tends to replace the mode-locked regime.

In conclusion, we have demonstrated what is believed to be the first $\mathrm{Yb}$ :BOYS mode-locked oscillator.
This crystal gives very promising results, since it combines a broadband emission (glasslike) spectrum and the high laser efficiency of crystals,$^{10}$ and pulses as short as 69 fs have been obtained. Tunability for sub-86-fs pulses of 1051-1070 $\mathrm{nm}$ was also achieved. With higher-power diode pumping, 300-mW average power (33-kW peak power) was obtained for $86-\mathrm{fs}$ pulses. Nevertheless, considering the broadness of the emission cross-section spectrum, we still have not taken advantage of full potential of Yb:BOYS. We are looking forward to improving our system for shorter-pulse generation by use of other more specifically designed SESAMs.

We acknowledge the financial support of the Société de Secours des Amis des Sciences for the postdoctoral position of F. Druon. His e-mail address is frederic.druon@iota.u-psud.fr.

\section{References}

1. D. S. Sumida, A. A. Betin, H. Bruesselbach, R. Bryen, S. Matthews, R. Reeder, and M. S. Mangir, Laser Focus World 35(6), 63 (1999).

2. C. Hönninger, R. Paschotta, M. Graf, F. Morier-Genoud, G. Zhang, M. Moser, S. Biswal, J. Nees, A. Braun, G. Mourou, I. Johannsen, A. Giesen, W. Seeber, and U. Keller, Appl. Phys. B 69, 3 (1999).

3. M. E. Fermann, A. Galvanauskas, G. Sucha, and D. Harter, Appl. Phys. B 65, 259 (1997).

4. P. H. Haumesser, R. Gaumé, B. Viana, E. Antic-Fidancev, and D. Vivien, J. Phys. Condens. Matter 13, 5427 (2001).

5. F. Druon, F. Balembois, P. Georges, A. Brun, A. Courjaud, C. Hönninger, F. Salin, A. Aron, F. Mougel, G. Aka, and D. Vivien, Opt. Lett. 25, 423 (2000).

6. H. Liu, J. Nees, and G. Mourou, in Conference on Lasers and Electro-Optics, Vol. 56 of OSA Trends in Optics and Photonics Series (Optical Society of America, Washington, D.C., 2001), pp. 30-31.

7. F. Brunner, G. J. Spühler, J. Aus der Au, L. Krainer, F. Mourier-Genoud, R. Paschotta, N. Lichtenstein, S. Weiss, C. Harder, A. A. Lagatsky, A. Abdolvand, N. V. Kuleskov, and U. Keller, Opt. Lett. 25, 1119$1121(2000)$.

8. P. H. Haumesser, R. Gaumé, B. Viana, G. Aka, and D. Vivien, " $\mathrm{Yb} b^{3+}$ lasers based on $\mathrm{Yb}$ doped $\mathrm{M}_{3} \mathrm{RE}\left(\mathrm{BO}_{3}\right)_{3}$ where $M=B a$, Sr and $R E=L u, Y, S c$," patent pending.

9. P. H. Haumesser, R. Gaumé, G. P. Aka, B. Viana, A. Kahn-Harari, and D. Vivien, in Advanced Solid-State Lasers, H. Injeyan, U. Keller, and C. Marshall, eds., Vol. 34 of OSA Trends in Optics and Photonics Series (Optical Society of America, Washington, D.C., 2000), pp. $555-560$.

10. S. Chénais, F. Druon, F. Balembois, P. Georges, R. Gaumé, P. H. Haumesser, B. Viana, G. P. Aka, and D. Vivien, J. Opt. Soc. Am. B 19, 1 (2002).

11. U. Keller, Appl. Phys. B 58, 347 (1994).

12. C. Hönninger, R. Paschotta, F. Morier-Genoud, M. Moser, and U. Keller, J. Opt. Soc. Am. B 16, 46 (1999). 